\title{
Tail-dominated storm main phase: 31 March 2001
}

\author{
R. M. Skoug, ${ }^{1}$ M. F. Thomsen, ${ }^{1}$ M. G. Henderson, ${ }^{1}$ H. O. Funsten, ${ }^{1}$ G. D. Reeves, ${ }^{1}$ \\ C. J. Pollock, ${ }^{2}$ J.-M. Jahn, ${ }^{2}$ D. J. McComas, ${ }^{2}$ D. G. Mitchell, ${ }^{3}$ P. C. Brandt, ${ }^{3}$ B. R. Sandel, ${ }^{4}$ \\ C. R. Clauer, ${ }^{5}$ and H. J. Singer ${ }^{6}$
}

Received 30 September 2002; revised 12 February 2003; accepted 26 February 2003; published 26 June 2003.

[1] On 31 March 2001 a fast solar wind transient with strong southward interplanetary magnetic field $\mathrm{B}_{\mathrm{z}}$ produced a large geomagnetic storm at Earth, with a drop in the Dst index to $-350 \mathrm{nT}$ between 0400 and 0900 UT. The Earth's magnetosphere was very compressed during this interval, with the bow shock crossing geosynchronous orbit on at least two occasions. Here we present space-based and ground-based observations demonstrating that tail currents, rather than ring currents, were the dominant contributor to the Dst index during the main phase of this storm. The plasma sheet during this interval was exceptionally dense and penetrated very deeply towards the Earth, leading to extremely strong tail currents flowing quite close to the Earth. These tail currents produced a very distorted magnetosphere, with strong stretching of the magnetic field lines in the nightside plasma sheet. Energetic neutral atom (ENA) images from the MENA and HENA instruments on IMAGE show a very narrow spatial distribution, with ENAs confined to the nightside until a magnetic field dipolarization at $\sim 0630$ UT when Dst was $-250 \mathrm{nT}$. Ground magnetometer measurements confirm that the disturbance was localized on the nightside and dominated by tail currents up until the field dipolarization. Following the dipolarization, higher energy ENAs began to drift toward dusk, forming a partial ring current. Even at that time, low-energy ENAs were not observed on the dayside, either due to inhibited access or to strong charge exchange losses. INDEX TERMS: 2708 Magnetospheric Physics: Current systems (2409); 2788 Magnetospheric Physics: Storms and substorms; 2740 Magnetospheric Physics: Magnetospheric configuration and dynamics; 2720 Magnetospheric Physics: Energetic particles, trapped; 2730 Magnetospheric Physics: Magnetosphere—inner; KEYWORDS: tail current, geomagnetic storm, Dst index, ENA imaging

Citation: Skoug, R. M., et al., Tail-dominated storm main phase: 31 March 2001, J. Geophys. Res., 108(A6), 1259, doi:10.1029/2002JA009705, 2003.

\section{Introduction}

[2] The relative contributions of various current systems to the Dst index during geomagnetic storms has been a subject of recent interest and debate. The Dst index is a measure of the strength of a geomagnetic storm and is calculated by an average of the horizontal $(\mathrm{H})$ component of the geomagnetic field measured at four low-latitude stations [Sugiura and Kamei, 1991]. Dst is often nominally considered to be a measure of the symmetric ring current. A ring current encircling the Earth produces a magnetic field

\footnotetext{
${ }^{1}$ Los Alamos National Laboratory, Los Alamos, New Mexico, USA.

${ }^{2}$ Southwest Research Institute, San Antonio, Texas, USA.

${ }^{3}$ Applied Physics Laboratory, Johns Hopkins University, Laurel, Maryland, USA.

${ }^{4}$ Lunar and Planetary Laboratory, University of Arizona, Tucson, Arizona, USA.

${ }^{5}$ Space Physics Research Laboratory, University of Michigan, Ann Arbor, Michigan, USA.

${ }^{6}$ NOAA Space Environment Center, Boulder, Colorado, USA.

Copyright 2003 by the American Geophysical Union. 0148-0227/03/2002JA009705
}

oriented opposite to the Earth's magnetic field, leading to the observed decreases in the $\mathrm{H}$ component of the field and thus in Dst during storms. The Dessler-Parker-Sckopke relation [Dessler and Parker, 1959; Sckopke, 1966] gives a linear relationship between the magnetic perturbation at the center of the Earth and the total kinetic energy of the ring current ions.

[3] However, it has long been recognized that other current systems can and do contribute to Dst, including partial ring currents, tail currents, and magnetopause currents [e.g., Gonzalez et al., 1994; Campbell, 1996; Kamide et al., 1998; Greenspan and Hamilton, 2000, and references therein]. The Dst* index was developed to remove contributions due to magnetopause currents [Burton et al., 1975] by subtracting a contribution due to the solar wind ram pressure. Currents induced in the Earth by magnetospheric and ionospheric currents can also make a significant contribution to Dst [e.g., Häkkinen et al., 2002].

[4] Many studies have noted that the ring current is often asymmetric and have considered contributions from the partial ring current to Dst [e.g., Akasofu and Chapman, 1964; Frank, 1970; Roelof, 1987; Greenspan and Hamilton, 
2000; Brandt et al., 2002]. A recent study [Liemohn et al., 2001] suggests that the partial ring current can be the dominant contributor to the Dst index during storms, with particles on open drift paths providing up to $80 \%$ of the Dst signature at the time of minimum Dst and making smaller contributions both earlier and later in the storm.

[5] Cross-tail currents also contribute to the Dst index, but the magnitude of the storm-time tail current contribution to Dst has not yet been resolved. Theoretical work [Kaufmann, 1987] has shown that large tail currents are required between 7 and $10 R_{E}$ to account for the magnetic field perturbations observed during storms. Some authors [e.g., Alexeev et al., 1996; Arykov and Maltsev, 1996; Dremukhina et al., 1999] have suggested that the tail current may be responsible for as much as $50-80 \%$ of the Dst index during storm times, contributing as much as or more than the ring current. Other studies [e.g., Turner et al., 2000, 2002; Ohtani et al., 2001] have found that the tail current can be responsible for $\sim 20-25 \%$ of the Dst variations during a storm, a significant although not dominant contribution.

[6] Tail currents and partial ring currents close in different locations (ring currents through field-aligned currents into the ionosphere and tail currents through ChapmanFerraro currents at the magnetopause) and can in theory be distinguished on this basis. In practice, however, measurement of the closure currents and thus definitive identification of the current system is a difficult task. The question of tail current or partial ring current identification can then become a question of semantics. In fact it appears that at least part of the difference between the varying tail current contributions discussed in the previous paragraph may simply be due to differing definitions of tail currents and partial ring currents [Maltsev and Ostapenko, 2002; Turner et al., 2002]. In the absence of information about current closure, in this paper we will use the term tail current to refer to currents that are caused by particles confined to the nightside of the Earth. Ring current, or partial ring current, will be used to describe currents due to ions that experience gradient-curvature drift westward around the Earth. We do not require that these particles be on closed drift paths but do require that they show evidence of drift around the Earth as opposed to simply across the geomagnetic tail.

[7] In this paper we present both space-based and groundbased observations supporting the idea that tail currents, rather than the ring current, dominated the Dst variations observed during the growth phase of a large geomagnetic storm observed on 31 March 2001. This storm was one of the largest of the current solar cycle, with Dst reaching $-350 \mathrm{nT}$. In addition this storm was well-observed by a number of spacecraft, including global energetic neutral atom (ENA) and ultraviolet (UV) images from the IMAGE satellite [Burch, 2000] as well as in situ measurements from the LANL and GOES geosynchronous satellites. This storm was of course not unique, and many of the storm characteristics which will be discussed below have also been observed in other storms, including day-night asymmetries [e.g., Roelof, 1987; De Michelis et al., 1997], strong convection [e.g., Wygant et al., 1998], large geomagnetic fields [e.g., Shiokawa et al., 1997], and a highly compressed magnetosphere [e.g., Hamilton et al., 1988; Rufenach et al., 1989]. How- ever, these studies have not addressed tail current contributions to the Dst index.

[8] ENA images, which measure charge exchange neutral atoms produced through the interaction of energetic magnetospheric ions with the neutral hydrogen exosphere, provide a new tool for studying the global dynamics of geomagnetic storms. Although magnetospheric ENA imaging has been performed from a variety of spacecraft [e.g., Roelof, 1987; Lui et al., 1996; Henderson et al., 1997; Brandt et al., 2001], the IMAGE mission [Burch, 2000] provides the first platform for global ENA imaging over a wide range of energies, together with UV and radio imaging. When combined with in situ and ground-based measurements, this complement of data provides a very complete picture of this geomagnetic storm. The ENA images obtained during the 31 March 2001 storm indicate that ions did not begin to drift westward, forming a partial ring current, until well after the storm was underway. Instead, the ENAs were confined to the nightside of the Earth until Dst had reached a value of nearly $-300 \mathrm{nT}$. Although it is possible that partial ring currents were responsible for a portion of the Dst signature, we demonstrate that the disturbance was confined to the nightside of the Earth throughout the main phase of this storm and provide plausible evidence that tail currents were indeed responsible for the observed geomagnetic disturbances.

\section{Observations}

[9] The 31 March 2001 geomagnetic storm was driven by a coronal mass ejection (CME) observed in the solar wind. Figures $1 \mathrm{a}$ and $1 \mathrm{~b}$ show the GSM z-component of the interplanetary magnetic field (IMF) and the solar wind dynamic pressure measured by the MAG [Smith et al., 1998] and SWEPAM [McComas et al., 1998] instruments, respectively, on the ACE spacecraft for 0000-1200 UT on 31 March. The solar wind parameters have been shifted in time to approximately account for the propagation from the spacecraft at L1 to the Earth. Propagation times were determined from 20-min running averages of the solar wind speed measured at ACE, assuming propagation parallel to the GSM x-axis. In the solar wind this event was first observed as a shock, seen by ACE at $~ 0022$ UT on 31 March, and observed at the Earth as a sudden impulse (SI), with the solar wind dynamic pressure reaching $100 \mathrm{nPa}$. The CME included a very strong southward interplanetary magnetic field, with $\mathrm{B}_{\mathrm{z}}$ taking on values of less than $-30 \mathrm{nT}$ intermittently over a period of nearly 7 hours and reaching a minimum value of nearly $-50 \mathrm{nT}$ at $\sim 0630 \mathrm{UT}$.

[10] These extreme solar wind conditions led to a highly disturbed magnetosphere and very strong magnetospheric convection. Dst (Figure 1c) dropped from near 0 to $-350 \mathrm{nT}$ between 0400 and $0900 \mathrm{UT}$ and then recovered gradually over the next 3-4 days. The red line in Figure 1c shows the Sym-H index, a high-resolution (1 min) version of Dst. The large negative IMF $B_{z}$ values produced an extremely strong convective electric field during much of the main phase of the storm. This strong convection persisted until $\sim 0800$ UT, when the IMF turned northward. To study the magnetospheric response, we first examine magnetospheric images from the IMAGE spacecraft and then show 


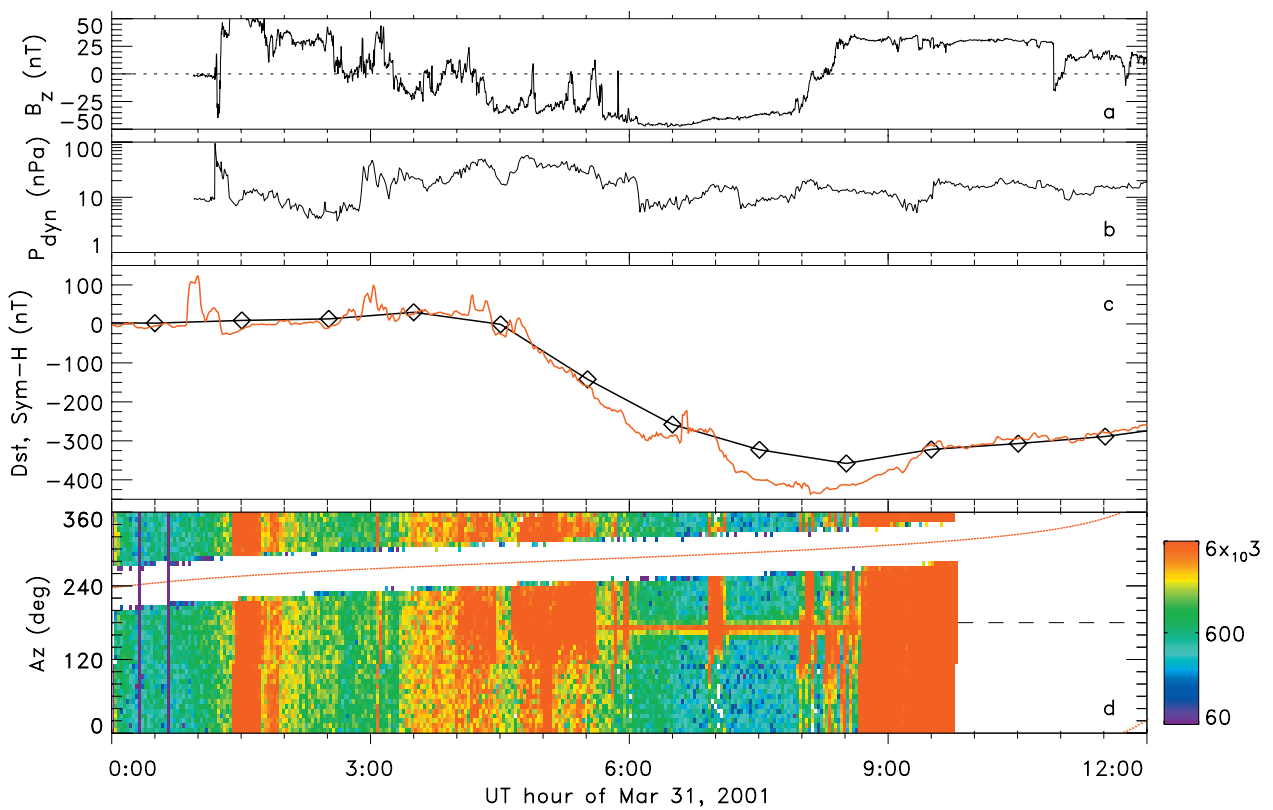

Figure 1. An overview of the 31 March 2001 storm, showing parameters from 0000-1200 UT. (a) IMF $\mathrm{B}_{\mathrm{z}}$ (nT) measured by ACE/MAG. (b) The solar wind dynamic pressure (nPa) measured by ACE/ SWEPAM. (c) The Dst index (black) and the Sym-H index (red), both in nT. (d) 5-12 keV ENAs counts measured by MENA as a function of spacecraft spin angle and time.

measurements of magnetospheric particles and fields from geosynchronous orbit and from ground-based magnetometers. Figure 2 shows the locations of spacecraft used for this study. Note that in the bottom panel the GSM $x$ and $y$ axes point to the left and bottom of the figure, respectively. Thus the Sun (local noon) is to the left, local dusk is at the bottom, local midnight is to the right, and local dawn is at the top. During this storm, the LANL geosynchronous satellite 1991-080 (red diamonds) was on the dusk side of the Earth, and GOES-8 (black stars) was on the nightside, also at geosynchronous orbit. IMAGE (blue crosses) was moving over the north pole in an orbit with apogee of $\sim 8 \mathrm{R}_{\mathrm{E}}$, in a plane nearly aligned with the Earth-Sun line.

\subsection{Magnetospheric Images}

[11] Figure 1d shows 5-12 keV ENAs measured by the Medium Energy Neutral Atom (MENA) imager [Pollock et al., 2000] on the IMAGE spacecraft from 0000-1200 UT on 31 March. MENA measures energetic neutral atoms at energies from $\sim 1-30 \mathrm{keV}$ with approximately $4^{\circ} \times 8^{\circ}$ anangular resolution and $2 \mathrm{~min}$ time resolution. Data are shown in a spectrogram format, with the logarithmic color scale indicating ENA counts as a function of spacecraft spin angle and time. The Earth is located at $180^{\circ}$, and the Sun is indicated by the red line. To protect the microchannel plate detectors, MENA does not collect data when the instrument is looking within $\sim 20^{\circ}$ of the Sun or when the spacecraft is within the Earth's radiation belts (after $\sim 0945$ UT in Figure 1d). Because the magnetosphere was extremely compressed during this interval, IMAGE was located in the magnetosheath for several hours on 31 March. Magnetosheath intervals are identified by bright emissions around the sunward direction, such as observed from $\sim 0400-$ 0430 UT, $0440-0500 \mathrm{UT}, \sim 0510-0540 \mathrm{UT}$, and $\sim 0650-0710$ UT. The location of IMAGE in the magneto- sheath has also been identified by the Radio Plasma Imager (RPI) instrument on IMAGE [Reinisch et al., 2000] from the observation of waves typical of the magnetosheath rather than the magnetosphere (J. Green, personal communication, 2001). The relatively large, isotropic background in this panel is due to a combination of high energy penetrating radiation (mainly solar energetic particles) and charged particles with sufficiently high energy that they are not stopped by the MENA collimator. At times, such as from $\sim 0125$ to $0140 \mathrm{UT}, \sim 0500$ to $0510 \mathrm{UT}$, and $\sim 0835$ to $0950 \mathrm{UT}$, this background dominates the observation, obscuring any neutral atom signal. Magnetospheric ENAs, seen as a band of emissions around the Earthward direction, were observed starting at $\sim 0540$ UT. These emissions were much narrower in the spin angle direction than is typical, occupying only $1-2$ pixels $\left(8-16^{\circ}\right)$ in spin angle, with strong ENA emissions observed only very near the Earth during this storm. It is interesting to note that no magnetospheric ENA signal was observed at earlier times, even when the spacecraft was within the magnetosphere, such as from $\sim 0200$ to 0330 UT and around 0430 UT.

[12] The top panels of Figure 3 show 4-min averaged MENA images of 2-5 keV ENAs in a fisheye projection from 31 March (Figures 3a-3d) and 1 April (Figures 3e-3g), together with the Dst index (Figure $3 \mathrm{~h}$ ). White lines indicate dipole magnetic field lines at $\mathrm{L}=4$ and $\mathrm{L}=8$ for local times of $0000,0600,1200$, and 1800 LT. The apparent change in color scale on 1 April is due to a reduction of the background level. These images show that emissions on 31 March were confined to the nightside hemisphere and localized quite near the Earth, within $\sim 4 \mathrm{R}_{\mathrm{E}}$. MENA typically observes ENA fluxes out to distances of $6-8 R_{E}$ during storms and substorms. Not until the storm recovery phase, on 1 April, were significant ENAs in this energy range observed on the dayside. Some dayside ENAs were 


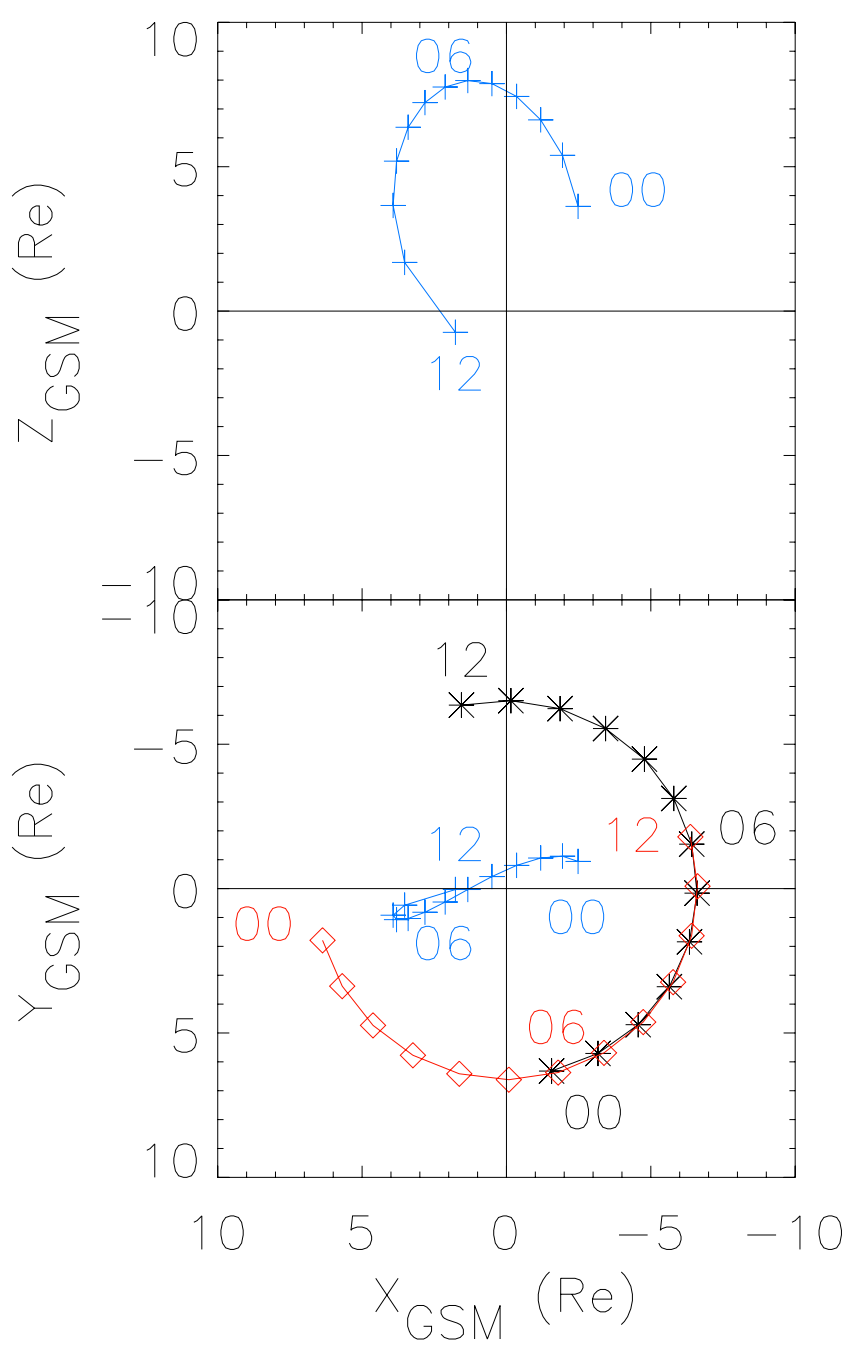

Figure 2. Locations of LANL geosynchronous satellite 1991-080 (red diamonds), GOES-8 (black stars), and IMAGE (blue crosses) in the GSM $x-y$ (bottom) and $x-z$ (top) planes from 0000-1200 UT on 31 March 2001. In the bottom panel, the Sun (local noon) is to the left with local dusk at the bottom.

also present in the 31 March, 1534 UT image, coincident with a partial recovery of the Dst index.

[13] Figures 3i-3o show images from the High Energy Neutral Atom (HENA) imager [Mitchell et al., 2000] on the IMAGE spacecraft from 0600-0900 UT on 31 March, around the time of minimum Dst (blue bar in Figure $3 \mathrm{~h}$ ). HENA measures $\sim 20-500 \mathrm{keV}$ ENAs with approximately $6^{\circ} \times 6^{\circ}$ angular resolution and 2-min time resolution. Figures $3 \mathrm{i}-3 \mathrm{o}$ show 4-min averages of 50-60 keV ENAs in the same format as the MENA images. The viewing geometry changes by a sufficiently small amount over this 3-hour interval that the gradient-curvature drift of the particles can be seen. Early in the storm, at 0600 UT, the images were similar to the lower energy MENA images, with emissions confined to the nightside near the Earth. Beginning at $\sim 0630$ UT, however, these higher-energy particles began to drift into the afternoon sector, forming a partial ring current. The drift increased following the reduction of the convective electric field at $\sim 0800$ UT.
By 0900 UT the 50-60 keV ions formed nearly a complete ring current around the Earth.

[14] ENA imagers measure integrated ENA fluxes along the line of sight of each pixel, complicating the threedimensional localization of ion sources, particularly from certain viewing geometries. Optimal viewing occurs when the spacecraft is nearly over the pole of the Earth. However, meaningful images are obtained over a range of viewing geometries, in particular providing reliable information concerning the local time dependence of ENAs [e.g., Pollock et al., 2001; Mitchell et al., 2001; Reeves et al., 2002]. Viewing geometry changes slowly around spacecraft apogee, providing good observations over extended periods of time. The pitch angle distribution of the parent ion distribution also affects the observed images [Moore et al., 1995]. However, ENA fluxes are predicted to be qualitatively similar over a range of pitch angle distributions [Moore et al., 1995], so we do not expect variations in the pitch angle distribution to obscure the major features of the images. A full study of pitch angle effects requires inversion of the images using a method which accounts for the pitch angle distribution, a task beyond the scope of this paper.

[15] Figure 4 shows images of the plasmasphere on 3031 March obtained by the Extreme Ultraviolet (EUV) imager [Sandel et al., 2000] on IMAGE. EUV measures the $\mathrm{He}^{+} 30.4 \mathrm{~nm}$ emission with 10 -min time resolution for remote sensing of the plasmasphere. The sunward direction is toward the bottom of each panel. The black regions at the bottom of each image arise because the detector high voltages are reduced when looking at the Sun to avoid high count rates from scattered sunlight and radiation noise. The darker region at the top of each image, opposite the Sun, is the Earth's shadow. The tan curve in each panel is a circle at $\mathrm{L}=3$ in the plane of the magnetic equator, projected onto the image plane. White arcs in Figures $4 \mathrm{~b}-4 \mathrm{e}$ mark the plasmapause location in the plane of the image.

[16] To establish the initial conditions in the plasmasphere before the onset of the storm, we rely on images such as Figure 4a, taken at 1606 UT on 30 March, approximately 12 hours before the beginning of the decline in Dst. This image is particularly useful because it shows the position of the plasmapause at all local times. Furthermore, the high magnetic latitude $\left(86^{\circ}\right)$ of the viewpoint minimizes the effects of geometric distortion that can arise in projecting the three-dimensional source region onto the plane of the image. Prior to the storm, the plasmapause was near $\mathrm{L}=4$ at most local times. In the morning sector it dipped inward to about $\mathrm{L}=3$, and near dusk it extended outward to about $\mathrm{L}=6$ in a bulge with a suggestion of a drainage plume.

[17] Figure $4 \mathrm{~b}$ shows the plasmasphere at 0258 UT, shortly before the storm began. At the local times for which the plasmapause was visible, it was at roughly the same radial distance as in Figure 4a. In contrast, at 0613 UT (Figure 4c) the plasmasphere was very compressed on the nightside and in the dawn sector. It was not visible in Earth's shadow, but at the edges of the shadow (MLT 0300 and 2100) the plasmapause was near $\mathrm{L}=2.3$. An extensive drainage plume extended sunward from near the dusk meridian. By 0634 UT (Figure 4d) the plasmapause had 

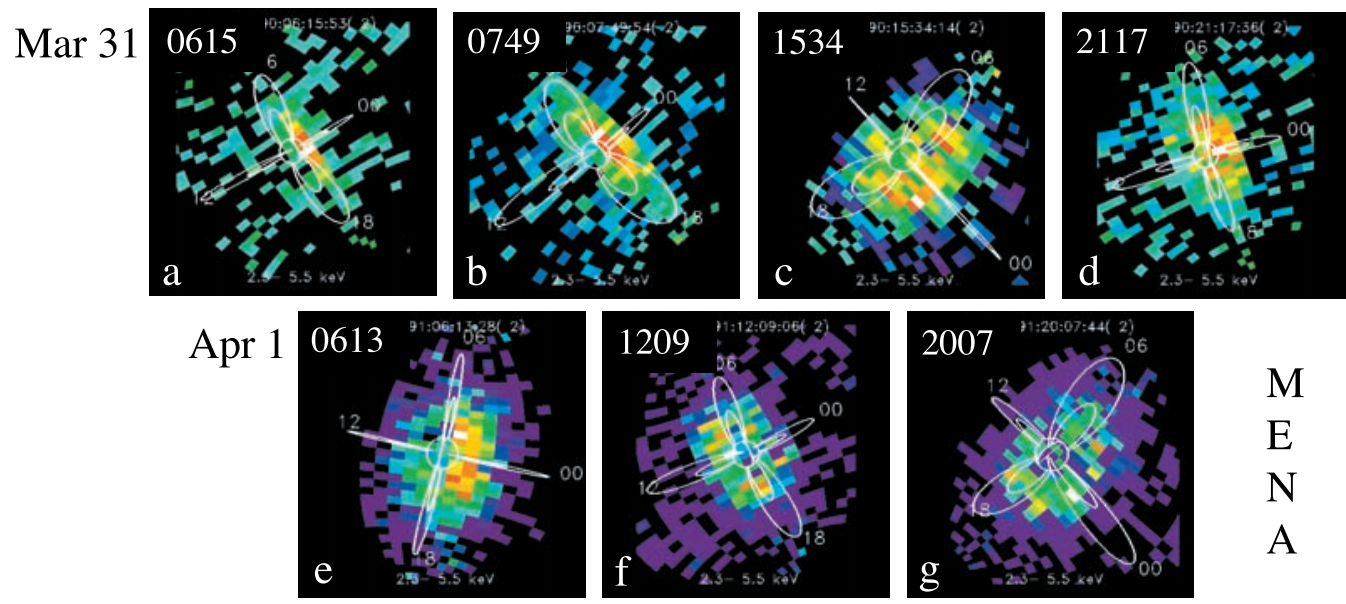

M
E
N
A
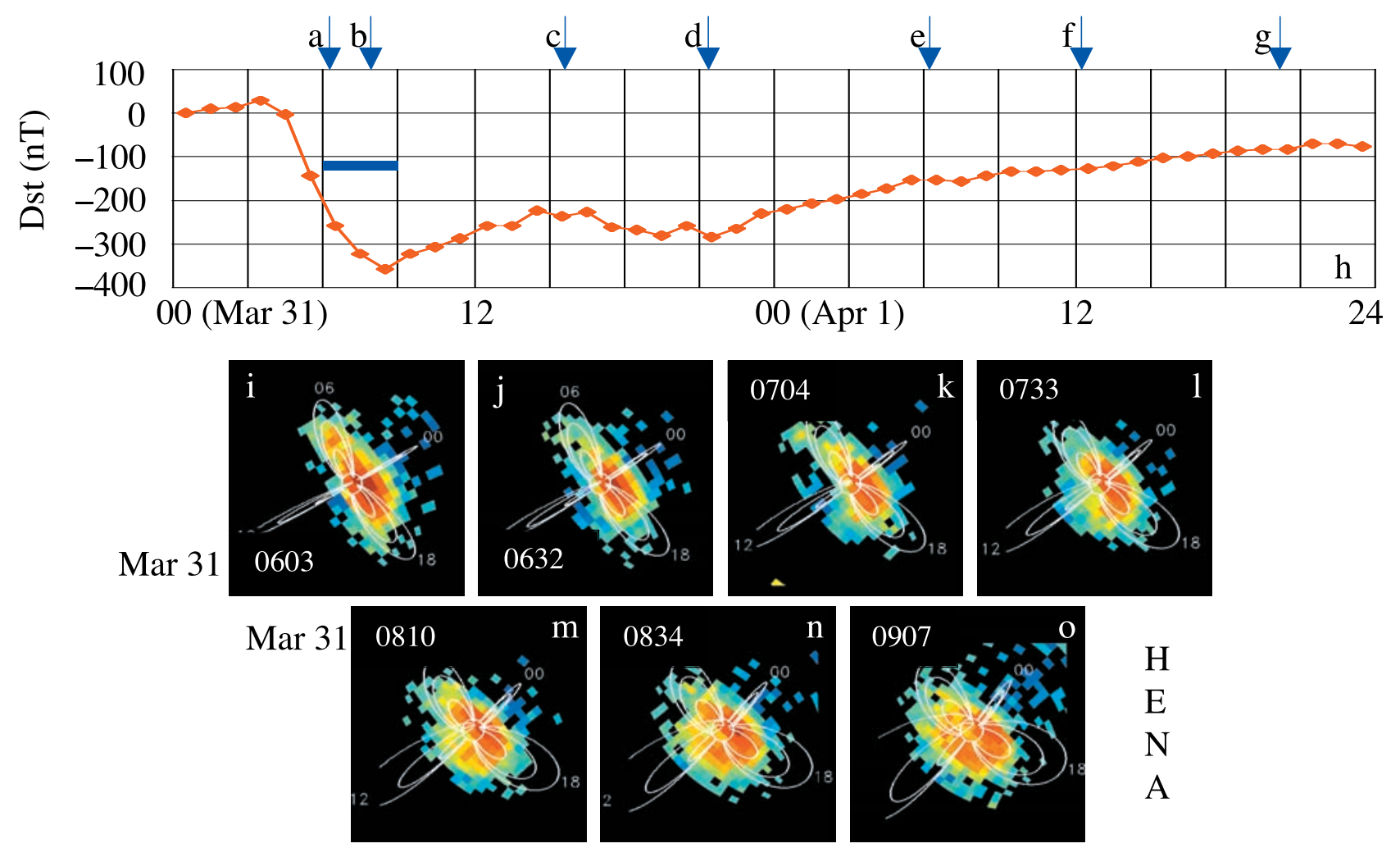

Figure 3. (a-g) Four-minute averaged MENA images of 2-5 keV ENAs in a fisheye projection from 31 March (Figures 3a-3d) and 1 April (Figures 3e-3g) 2001. Image times are indicated by the blue arrows at the top of Figure 3h. Figure $3 \mathrm{~h}$ shows the Dst index (nT) for 31 March-1 April 2001. Figures 3i-3o show 4-min averaged HENA images of 50-60 keV ENAs in a fisheye projection from 31 March 2001. HENA images are shown approximately every half hour over the period covered by the horizontal blue line in Figure 3h.

even moved further inward, to approximately $\mathrm{L}=2.0$ at the same local times.

[18] In addition, these images show the auroral oval and are in fact the only space-based auroral observations available for this storm, since the auroral imagers on both the Polar and IMAGE spacecraft were turned off during this period. The EUV instrument is sensitive (at reduced levels) to wavelengths up to $\sim 80 \mathrm{~nm}$, and the observed EUV auroras are most likely due to the $53.9 \mathrm{~nm} \mathrm{O}^{+}$line [Paresce et al., 1983; Chakrabarti, 1985]. The storm-time auroral images follow the same pattern as the higher-energy ENA images (Figures 3i-3o), with auroras observed only on the nightside at $0613 \mathrm{UT}$, extending onto the dusk side at 0634 UT and forming a nearly complete auroral oval by 0756 UT (Figure 4e). A relatively dim but complete auroral oval was also observed prior to the storm at $0258 \mathrm{UT}$.

[19] These EUV images are rather low in contrast because of two sources of noise. In Figure 4b, Earth is near the edge of the range of spin phases for which the detector gain is reduced to protect against direct and scattered sunlight, and the region near Earth shows some effects of scattering. At later times, the storm-induced high-energy particle environ- 

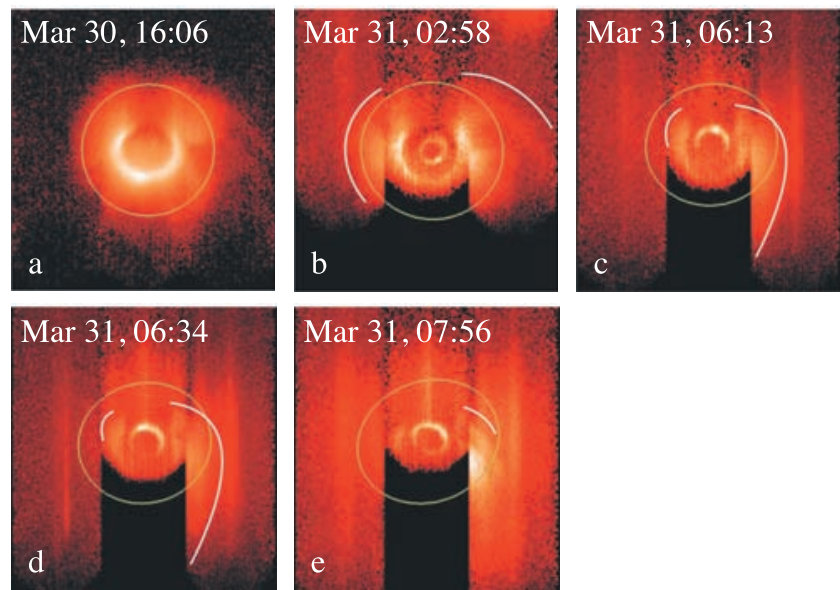

Figure 4. EUV images of the plasmasphere before and during the 31 March 2001 storm. (a) 30 March, 1606 UT, viewing from a magnetic latitude of $86^{\circ}$ (b) 31 March, $0258 \mathrm{UT}$, viewing from $83^{\circ}$ (c) $31 \mathrm{March}, 0613 \mathrm{UT}$, viewing from $67^{\circ}$ (d) 31 March, $0634 \mathrm{UT}$, viewing from $64^{\circ}$ and (e) 31 March, $0756 \mathrm{UT}$, viewing from $58^{\circ}$ The closed tan curve in each panel is a circle in the plane of the magnetic equator at $\mathrm{L}=3$. The white $\operatorname{arcs}$ in Figures $4 \mathrm{~b}-4 \mathrm{e}$ mark the location of the plasmapause in the plane of the image over the range of azimuths for which it can be reliably determined. ment leads to noise which, in combination with bright signals from Earth, triggers an over-rate protection algorithm in the central camera from time to time. We have normalized the images to a common exposure time, but the lower than normal duty cycle leads to an unrecoverable loss in statistical accuracy. The vertical stripes near the center of each of the three cameras are further manifestations of this noise. In spite of the low contrast, the main features of the plasmasphere are discernible, especially by viewing several images in sequence.

\subsection{In Situ Observations}

[20] In situ measurements of the 31 March 2001 storm from geosynchronous orbit are given in Figure 5. Figure 5a shows the electron energy spectrogram measured by the Magnetospheric Plasma Analyzer (MPA) instrument [Bame et al., 1993] on the LANL geosynchronous satellite 1991080 , located at $164.2 \mathrm{~W}^{\circ}$ geographic longitude. The logarithmic color bar indicates counts as a function of energy $(1 \mathrm{eV}-45 \mathrm{keV})$ and time. During this extremely disturbed interval the bow shock actually crossed geosynchronous orbit [Ober et al., 2002], seen at satellite 1991-080 from $\sim 0058$ to 0102 UT. Although this brief encounter with the unshocked solar wind is not visible on the 12-hour time scale of Figure 5, high-resolution data show the same features described by [Ober et al., 2002], including highly

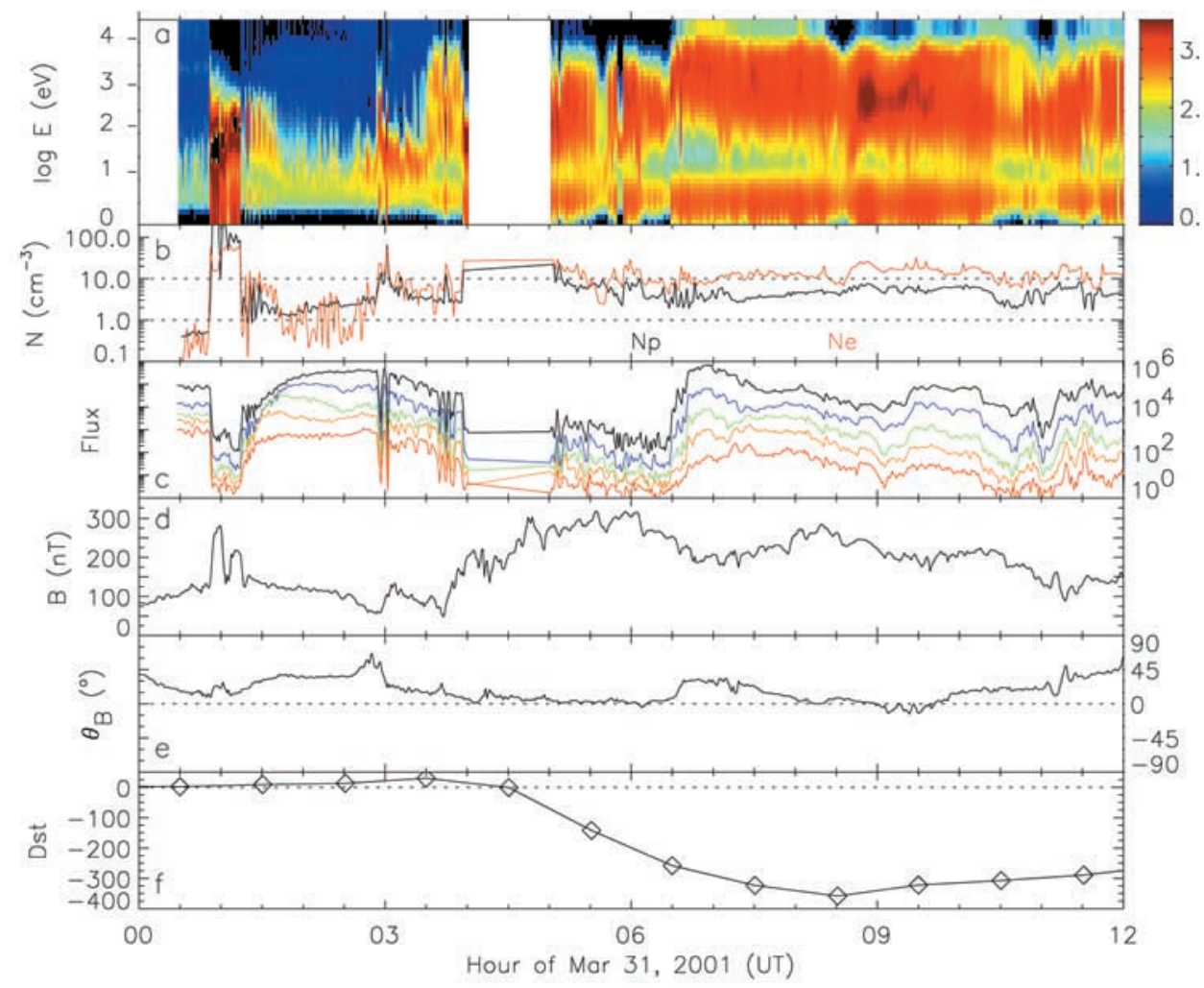

Figure 5. In situ measurements from geosynchronous orbit from 0000-1200 UT on 31 March 2001. (a) $1 \mathrm{eV}-45 \mathrm{keV}$ electron counts as a function of energy and time. The color bar gives the log of the counts. (b) Hot ion (black) and electron (red) density $\left(\mathrm{cm}^{-} 3\right)$, (c) the flux of 50-315 keV electrons $\left(\mathrm{cm}^{2} \mathrm{~s}\right.$ $\mathrm{sr} \mathrm{keV}^{-} 1$, (d) the magnitude of the geomagnetic field (nT), (e) the magnetic field tilt angle (deg), with $90^{\circ}$ indicating a dipolar field, and (f) the Dst index (nT). 
directional ions narrowly peaked around $2 \mathrm{keV}$ and intense fluxes of electrons at energies below $100 \mathrm{eV}$. With the exception of the brief interval, the spacecraft was located in the magnetosheath from $\sim 0050-0115$ UT, indicated by intense fluxes of $<1 \mathrm{keV}$ electrons, a lack of high energy plasma sheet electrons $(>10 \mathrm{keV})$, and ions peaked near $1-2 \mathrm{keV}$

[21] During the 31 March storm the electron plasma sheet was encountered at earlier local times than usual, beginning at $\sim 1630$ LT at satellite 1991-080 ( 0330 UT, Figure 2$)$. Entry into the electron plasma sheet is indicated by the appearance of hot electrons in Figure 5a at energies $>100 \mathrm{eV}$ with a peak near $1-2 \mathrm{keV}$. The local time at which the plasma sheet is encountered depends on the strength of magnetospheric convection [e.g., Korth et al., 1999; Elphic et al., 1999], with the plasma sheet observed at 1630 LT only under conditions of very strong convection.

[22] Figure 5b shows hot ion and electron densities calculated from MPA measurements on satellite 1991-080. The ion density (black) was calculated from measurements of $0.13-45 \mathrm{keV} / \mathrm{q}$ ions, and the electron density (red) from $0.03-45 \mathrm{keV} / \mathrm{q}$ electrons. The plasma sheet density observed by satellite 1991-080 was significantly higher than the typical plasma sheet density of $\sim 0.75 \mathrm{~cm}^{-3}$ [Korth et al., 1999], with electron densities of $5-10 \mathrm{~cm}^{-3}$ observed throughout the main phase of the storm. Elevated electron densities prior to 0330 UT are due to magnetosheath and boundary layer plasmas and to the presence of unusually hot lower-energy plasmaspheric material. The difference between the ion and electron densities after 0600 UT is most likely due to the presence of significant amounts of oxygen, which leads to underestimation of the ion density when it is calculated assuming the particles are protons [Thomsen et al., 1996]. The calculated densities indicate that oxygen was dominant at these times, with an inferred oxygen/proton density ratio of $\sim 2-10$ (assuming the MPA instrument actually measured the full ion and electron distributions).

[23] Figure 5c shows the fluxes of $50-315 \mathrm{keV}$ electrons observed on 31 March 2001 by the higher-energy Synchronous Orbit Particle Analyzer (SOPA) instrument [Belian et al., 1992] on the LANL geosynchronous satellite 1991-080. The dip in flux around 0100 UT was caused by spacecraft entry into the magnetosheath. A particle injection occurred at 0629 UT, when the satellite was at $\sim 1930$ LT (Figure 2). The injection was also observed in the $50-400 \mathrm{keV}$ proton fluxes (not shown). At the time of the injection, Dst was approximately $-250 \mathrm{nT}$ (Figure 5f).

[24] Figures 5d and 5e show the magnetic field magnitude and polar angle (GSM coordinates) measured on 31 March 2001 by the GOES-8 geosynchronous satellite [Singer et al., 1996], located at $75.3^{\circ} \mathrm{W}$ geographic longitude. The magnetic field was extremely intense during this interval, reaching values of over $300 \mathrm{nT}$, as compared with typical values of $\sim 100 \mathrm{nT}$. In addition, the field was extremely stretched, with field polar angles of approximately $0^{\circ}$ (i.e., essentially a radial field) around the time of maximum field strength, from 0400-0600 UT when GOES-8 was between 2300 and 0100 UT (Figure 2). The magnetic field dipolarized at $\sim 0634$ UT, with a drop in the field strength and a return to a less stretched configuration. The field dipolarization was nearly coincident with the particle injection. At the time of this dipolarization, GOES-8 was located at $\sim 0130$ LT (Figure 2). Conditions remained disturbed even after the dipolarization, with an increase in field strength and a return to a highly stretched configuration by 0800 UT, when GOES- 8 was at 0300 LT.

\subsection{Ground-Based Measurements}

[25] Figure 6 is a LT-UT map of the world-wide magnetic disturbance field measured by 19 low-latitude ground magnetic observatories using the method developed by Clauer and McPherron [1974] and updated by Clauer et al. [2002]. Universal time from 2000 UT on 30 March to 2000 UT on 31 March 2001 is shown on the horizontal axis. Magnetic local time (MLT) or equivalently position around the Earth is shown on the vertical axis with local midnight at the center and local noon at the top and bottom. The quiet-time field has been removed from the data using observations from the quiet day 15 March 2001. The axial component (parallel to the dipole axis) of the disturbance field is plotted using $50 \mathrm{nT}$ contours. Blue indicates positive disturbances and red indicates negative disturbances. The effect of the large solar wind pressure pulse was seen in the ground magnetic observations at $0058 \mathrm{UT}$ as a $150 \mathrm{nT}$ jump in the highresolution (1-min) Dst-equivalent index derived from the measurements used to produce Figure 6 (not shown) and also seen as a $\sim 130 \mathrm{nT}$ increase in the Sym-H index (Figure 1c). Rather than producing a world-wide field compression as is typical for a storm sudden commencement (SSC), this event produced a field enhancement which was greatest in the night sector but showed little change in the noon sector. This type of SSC or SI has been discussed by Clauer et al. [2001] as being due to a transition field-aligned current system formed in response to the northward turning of the IMF (Figure 1). The storm main phase began at $\sim 0420$ UT with a sustained decrease in the high-resolution Dst index and a surface magnetic field depression (Figure 6). The field depression was not uniform around the Earth. The depression was largest in the local time sector from 2100 MLT to 0500 MLT reaching a maximum depression at $\sim 0730$ UT of slightly over $-500 \mathrm{nT}$ at $0200 \mathrm{MLT}$. Throughout the main phase, the field depression remained centered slightly post midnight. At 0630 UT the rate of field decrease in the dusk sector increased. The dusk depression reached values slightly over $-400 \mathrm{nT}$ at $\sim 0800 \mathrm{UT}$.

\section{Discussion}

[26] All portions of the magnetosphere were highly distorted by the extreme event on 31 March 2001. The high solar wind dynamic pressure led to strong compression of the magnetosphere, with both the magnetopause and the bow shock crossing geosynchronous orbit at several times throughout the day [Ober et al., 2002]. The large negative values of the IMF $B_{z}$, nearly $-50 \mathrm{nT}$, drove unusually strong convection in the magnetosphere. The plasmapause boundary was very close to the Earth on the nightside, observed in EUV images at $\sim \mathrm{L}=2$ by $0634 \mathrm{UT}$, indicating very deep penetration of the plasma sheet towards the Earth. Geosynchronous observations of the plasma sheet at early afternoon local time $(\sim 1630$ LT) also reflect the deep sunward plasma sheet penetration. In addition, the plasma sheet was extremely dense, with unusually high densities of 


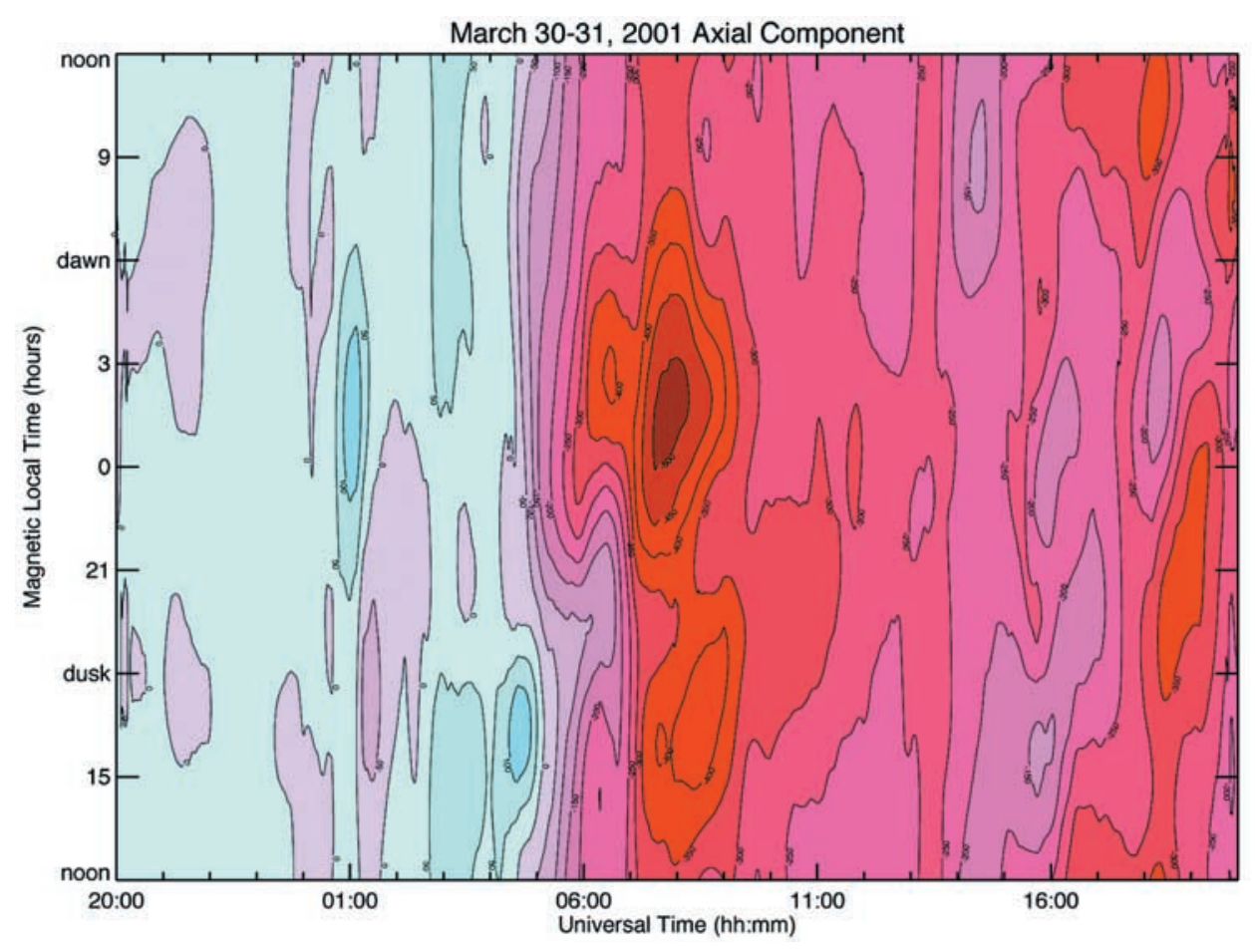

Figure 6. A LT-UT map of the axial component of the world-wide magnetic disturbance field measured by 19 low-latitude ground magnetic observatories from 2000 UT on 30 March 2001 to 2000 UT on 31 March 2001. The quiet-time field has been removed from the data using observations from the quiet day 15 March 2001. The contour step is $50 \mathrm{nT}$, with blue indicating positive disturbances and red negative disturbances.

$5-10 \mathrm{~cm}^{-3}$ (compared with typical values of $\sim 0.75 \mathrm{~cm}^{-3}$ [Korth et al., 1999]) measured over a wide range of local times extending onto the dayside.

[27] Magnetometer observations from geosynchronous orbit show large distortions in the nightside geomagnetic field. The field strength was nearly three times larger than typical, and the $\mathrm{B}_{\mathrm{z}}$ component was approximately zero at the time of maximum $B$, indicating a highly stretched field. Such a stretched field configuration requires strong tail currents, consistent with the observed high density of plasma sheet current carriers and the strong cross-tail convective electric field. If we assume that this $300 \mathrm{nT} \mathrm{B}_{\mathrm{x}}$ magnetic field is due to an infinite sheet of current in the $x-y$ plane, Ampere's Law says that the tail current density required to support the field will be $\mathrm{j}=2 \mathrm{~B} / \mu_{0}=0.5 \mathrm{~A} / \mathrm{m}$ in the $\mathrm{y}$ direction. This tail current is much larger than typically observed [e.g., Kaufmann, 1987].

[28] Ground magnetometer observations indicate that the currents responsible for the 31 March disturbance were strongest on the nightside, from 2100 MLT to 0500 MLT. The dominance of the negative nightside magnetic field perturbation is most consistent with an enhanced tail current. Negative duskside perturbations, as would be expected from a partial ring current, were relatively weak prior to 0700 UT, following the dipolarization and particle injection. The duskside field depression which began at $\sim 0630$ UT is consistent with an enhancement of the partial ring current, as was observed by HENA starting at approximately the same time. However, the continued strengthening of the nightside perturbation strongly suggests that the surface field response during the storm main phase development (0430-0900 UT)was dominated by tail currents.

[29] Field-aligned currents could also contribute to the disturbances observed at the ground [e.g., Fujii et al.,1992]. Enhanced Region 1 currents would produce a negative magnetic field perturbation on the dayside with a positive perturbation on the nightside, opposite to the nightside perturbation produced by a tail current. The presence of Region 1 currents would thus lead to an underestimation of the tail current effects during the main phase of the storm. Region 2 currents, on the other hand, would produce a positive perturbation on the dayside with a negative perturbation on the nightside. Such currents may have been important from 0400-0500 UT, when ground perturbations with this day-night asymmetry were observed (Figure 6). However, after 0500 UT the perturbation was negative at all local times, suggesting that field-aligned currents were not a dominant contributor to the ground disturbances during the main phase of the 31 March storm.

[30] Since ENAs result from charge exchange between magnetospheric ions and the cold neutral exosphere, significant numbers of ENAs are produced only in regions where both populations are sufficiently intense. The highly stretched geomagnetic field during the main phase of this storm may explain the lack of ENAs observed at moderate to large distances from the Earth. As shown in Figure 7, if the tail is very stretched, the plasma sheet will be very thin, and thus IMAGE lines of sight which cross the tail will intersect only a very thin region of intense ENA emissions, leading to a weak ENA signal at the spacecraft. In contrast, 


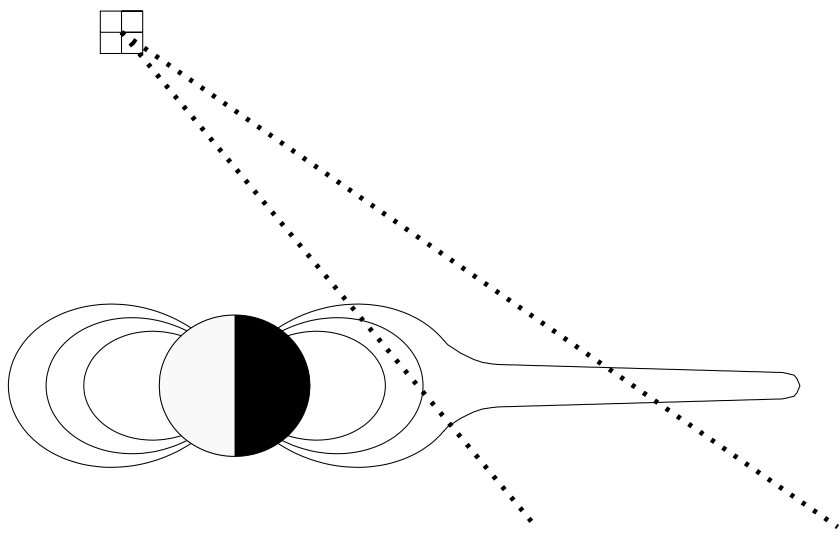

Figure 7. A sketch showing a distorted magnetosphere which a highly stretched tail. Lines of sight (dashed lines) from IMAGE (represented by the square) which cross the magnetosphere in the stretched tail intersect only a narrow region of ENA emissions. Lines of sight which pass closer to the Earth intersect a broader region of ENA emissions.

lines of sight which cross the magnetosphere near the Earth intersect thicker regions of high plasma density as well as higher exospheric densities and thus show high fluxes of neutral atoms. The lack of ENA fluxes beyond $\sim 4 R_{E}$ thus provides further evidence of a very stretched magnetotail and thus provides additional evidence for the existence of the strong tail currents which would be required to produce and maintain this configuration.

[31] To further demonstrate the plausibility of a tail current source for Dst, we have performed a simple calculation of the magnetic field perturbation caused by a tail current. Figure 8 shows the configuration used for this model. In this figure the axes are the GSM x, y, and $\mathrm{z}$ axes, and the Earth is shown as a sphere centered on $(0,0,0)$. For

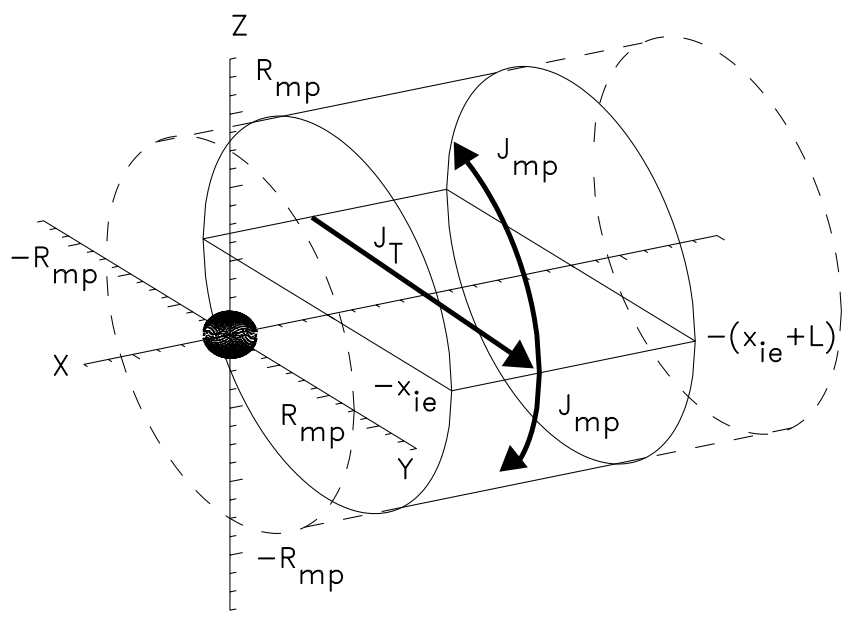

Figure 8. A sketch showing the configuration used to model the magnetic field due to a tail current. Axes are in GSM coordinates, with the Earth shown as a sphere centered on $(0,0,0)$. The magnetotail is modeled as a long cylinder parallel to the GSM x-axis, with tail currents flowing in the $x-y$ plane and magnetopause return currents at the boundary along a portion of the cylinder, from $\mathrm{x}=$ $-x_{\mathrm{ie}}$ to $\mathrm{x}=-\left(\mathrm{x}_{\mathrm{ie}}+\mathrm{L}\right)$.

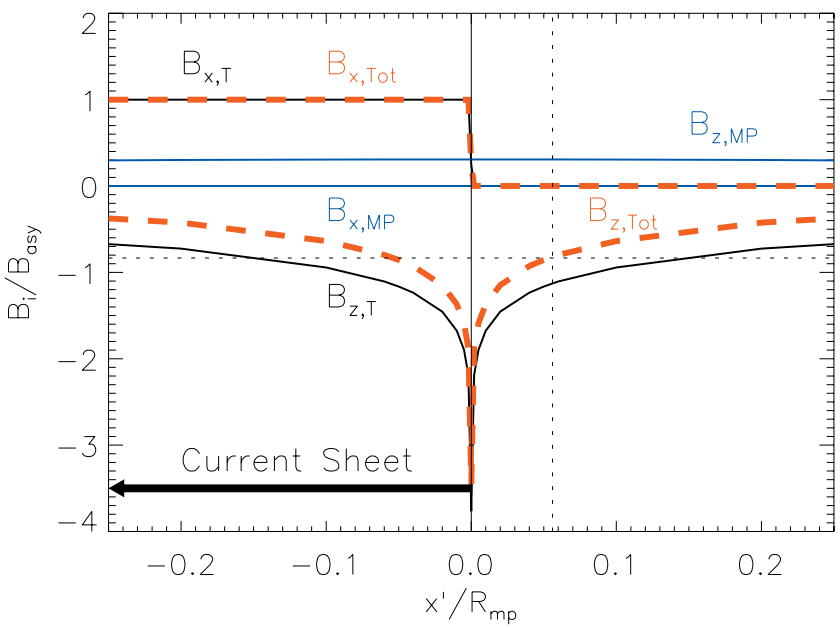

Figure 9. Magnetic field perturbations caused by tail current (black), magnetopause closure current (blue), and the sum of both currents (red) as a function of distance relative to the inner edge of the current sheet, from the calculation described in the text. Dotted lines indicate the magnetic field perturbation and current sheet location for 31 March 2001. See text for details.

this calculation the magnetotail is modeled as a cylinder of radius $R_{m p}$ parallel to and centered on the GSM x-axis. The tail current is modeled as a thin sheet in the $x-y$ (GSM) plane, extending from $-\mathrm{R}_{\mathrm{mp}}$ to $+\mathrm{R}_{\mathrm{mp}}$ in the $\mathrm{y}$ direction and from $-x_{i e}$ to $-\left(x_{i e}+L\right)$ in the $x$ direction, where $x_{i e}$ is the location of the inner edge of the plasma sheet on the nightside. In this region the tail current $J_{T}=\hat{y} j \delta(z)$, where $\mathrm{j}$ is a constant and $\delta(\mathrm{z})$ is the Dirac delta function. The magnetopause closure current $\mathrm{J}_{\mathrm{mp}}$ is assumed to flow on the cylindrical magnetopause, over the same range of $\mathrm{x}$ distances as the tail current. The magnetic field at the surface of the Earth is then obtained from integration of these currents using the Biot-Savart Law.

[32] The results of this calculation for a current sheet of length $\mathrm{L}=30 \mathrm{R}_{\mathrm{mp}}$ (i.e., approximately infinite) are given in Figure 9. The calculation was performed for positions in space along the GSM $x$ axis (i.e., $y=0, z=0$ ). The figure shows magnetic field perturbations due to the tail current $\left(\mathrm{B}_{\mathrm{x}, \mathrm{T}}, \mathrm{B}_{\mathrm{z}, \mathrm{T}}\right.$, in black), magnetopause closure current $\left(\mathrm{B}_{\mathrm{x}, \mathrm{MP}}\right.$, $B_{z, M P}$, in blue), and the sum of both currents $\left(B_{x, T o t}, B_{z, T o t}\right.$, in red) as a function of position $\mathrm{x}^{\prime}$ relative to the inner edge of the current sheet. Positions are normalized by the magnetopause distance $\mathrm{R}_{\mathrm{mp}}$, and $\mathrm{x}^{\prime}=0$ indicates the inner edge of the plasma sheet. Locations tailward of the inner edge are indicated by negative $\mathrm{x}^{\prime}$ and locations Earthward of the inner edge are indicated by positive $x^{\prime}$. The current sheet extends tailward from $\mathrm{x}^{\prime}=0$ to $\mathrm{x}^{\prime}=-\mathrm{L}$, as indicated by the black arrow near the bottom of the figure. Magnetic field perturbation values are scaled to the asymptotic $\mathrm{B}_{\mathrm{x}}$ component near the current sheet, measured for this case by GOES- 8 to be $B_{\text {asy }}=300 \mathrm{nT}$.

[33] Figure 9 shows that for $\mathrm{B}_{\mathrm{z}, \mathrm{Tot}}$ to reach the observed Dst value of $-250 \mathrm{nT}=-0.833 \mathrm{~B}_{\text {asy }}$ (horizontal dotted line), the measurement point on the surface of the Earth, at $(-1,0,0) R_{E} G S M$, must be located at a distance of approximately $\mathrm{x}^{\prime}=0.06 \mathrm{R}_{\mathrm{mp}}$ from the inner edge of the 
current sheet (vertical dotted line). A nominal magnetopause distance $R_{m p}=10 R_{E}$, an appropriate distance inthe tail for these extremely compressed conditions, then gives an inner edge distance $\mathrm{x}_{\mathrm{ie}}=1.6 \mathrm{R}_{\mathrm{E}}$ from the center of the Earth. This plasma sheet inner edge location is quite close to the Earth, consistent with the EUV measurements showing that the plasmapause and hence the inner edge of the plasma sheet was located at $2 \mathrm{R}_{\mathrm{E}}$ on the nightside. Another indication of such deep plasma sheet penetration was the ground-based observation of auroras, including fieldaligned arcs overhead, as far south as $40^{\circ}$ magnetic latitude, $\mathrm{L}=1.7$ (E. Dors and A. Jorgensen, Los Alamos National Laboratory, personal communication, 2001). Thus despite the simplicity of the calculation, these results show that tail currents of the size required to support the observed magnetic field configuration can produce large magnetic field perturbations at the surface of the Earth and so could have been responsible for the observed Dst signature.

[34] Calculations based on a more sophisticated numerical model of the tail current give a similar result [Tsyganenko and Sibeck,1994]. Tsyganenko and Sibeck [1994] developed a model of the tail current and magnetopause closure currents based on the T87 [Tsyganenko, 1987] magnetic field model and used this model to calculate magnetic field perturbations due to this current system. The resulting variations in $B_{x}$ and $B_{z}$ are shown in their Figures 6 and 7. Although the Tsyganenko and Sibeck [1994] results were derived for relatively quiet conditions, we can scale them to estimate the $\mathrm{B}_{\mathrm{z}}$ perturbations for 31 March. For the case shown by Tsyganenko and Sibeck [1994], a maximum $B_{x}$ perturbation of $\sim 23 \mathrm{nT}$ corresponds to a $B_{z}$ perturbation of $\sim-18 \mathrm{nT}$ at the surface of the Earth and a maximum $B_{z}$ perturbation of $\sim-37 \mathrm{nT}$ at the edge of the current sheet. If the tail current is increased to produce $\mathrm{B}_{\mathrm{x}}=300 \mathrm{nT}$ as observed on 31 March, the $\mathrm{B}_{\mathrm{z}}$ perturbation at the surface of the Earth will be $\sim-230 \mathrm{nT}$, a value which can account for nearly all of the observed Dst variation.

[35] Although the high densities observed at geosynchronous orbit from $0130-0400$ UT (1430-1700 LT) indicate the presence of significant ion fluxes in the afternoon sector, direct comparisons between the ENA and geosynchronous measurements are difficult, since the ENA images in this interval were contaminated by sunlight, magnetosheath particles, and high background radiation. However, the lack of Dst variations prior to 0430 UT indicates that the ions seen in the afternoon sector at geosynchronous orbit did not drift close enough to the Earth to cause magnetic field perturbations at the ground.

[36] During much of the main phase of the storm, from $\sim 0400-0630$ UT, while Dst dropped to $\sim-250 \mathrm{nT}$, almost no ENAs at energies from 1-60 keV were observed on the dayside of the Earth. ENA viewing in this interval was far less affected by contamination issues, and it is clear that nightside particles dominated the Dst effects. In this interval the geosynchronous satellite had moved into the dusk sector, where it observed extremely high densities at the same local times as the most intense ENAs fluxes. Apparently, the particle drift patterns during the storm main phase were such that particles were unable to reach the dayside before being lost. Following the particle injection and dipolarization at $\sim 0630 \mathrm{UT}$, the drift patterns changed, allowing higher energy ENAs $(50-60 \mathrm{keV})$ to begin to gradient-curvature drift towards dusk. The drift was further enhanced later in the event, following a northward turning of the IMF ( $\sim 0800$ UT, as observed at the Earth) and reduction of the convective electric field, leading to a nearly complete ring current by 0900 UT. However, lower energy ENAs $(1-30 \mathrm{keV})$ were not observed on the dayside until well into the recovery phase of the storm on 1 April 2001. This lack of particles could be due to inhibited access to the dayside or more probably to strong losses before the particles reach the dayside. Owing to the extremely high convective electric field, ring current particles were brought deep into the near-Earth region, leading to enhanced charge exchange losses. The diffuse red auroras observed at $\sim 40^{\circ}$ magnetic latitude (E. Dors and A. Jorgensen, Los Alamos National Laboratory, personal communication, 2001) were most likely caused by the resulting charge exchange neutrals.

[37] The EUV auroras observed by IMAGE show the same local time distribution as the higher-energy ENAs measured by HENA, with auroras during the storm observed only on the nightside prior to the $\sim 0630$ injection and dipolarization and then extending onto the dusk side following the injection. It is generally thought that EUV auroras in the wavelength range measured by IMAGE/EUV are caused by excitation of atmospheric $\mathrm{O}^{+}$[Paresce et al., 1983; Chakrabarti, 1985] by low-energy electrons high in the atmosphere [Gentieu et al., 1989; Rees, 1989]. However, the striking correspondence between the EUV and ENA measurements suggests that the EUV auroras during this event were associated with ions rather than electrons. The mechanism responsible for these auroras is thus not well understood.

[38] Convection patterns obtained from the Assimilative Mapping of Ionospheric Electrodynamics (AMIE) procedure (G. Lu, personal communication, 2002) are consistent with the observed particle confinement to the nightside. AMIE results show a strong convection cell on the dawnside, extending to low latitudes. On the nightside this dominantly dawnward convection would oppose the gradient-curvature drift, causing nightside particle stagnation. Moderate to strong duskward convection was not observed until after 0635 UT. In contrast to the dawnside convection, the weaker duskward convection at earlier times was observed only at high latitudes, corresponding to large geocentric distances. This asymmetry is consistent with the dayside observations of intense particle fluxes at geosynchronous orbit combined with weak ENA fluxes. The AMIE convection patterns suggest that even particles which reached geosynchronous orbit were unable to penetrate closer to the Earth, leading to a lack of ENA emissions beyond the dawn-dusk terminator.

[39] During this event a substorm injection and magnetic field dipolarization were observed nearly simultaneously at $\sim 0630$ UT. Ohtani et al. [2001] note that under such circumstances, the separation of tail current and ring current effects becomes more complicated. The combination of an injection and a dipolarization leads to competing contributions to the Dst index. The dipolarization reduces the tail current contribution and thus causes an increase in Dst (Dst becomes less negative), while the injection increases the ring current contribution, causing Dst to decrease (become more negative). An increase in Dst (Sym-H) has been 
observed to be a common feature of substorm injections [Iyemori and Rao, 1996]. Siscoe and Petschek [1997] have shown that this result can be explained if a large fraction (more than half) of the magnetic energy released by the dipolarization goes into heating of the ionosphere rather than into the ring current. Note (Figure 1c) that an increase in the Sym-H index was indeed observed at the $\sim 0630$ UT injection/dipolarization. The competing effects of the tail current and ring current can lead to underestimation of the tail current contribution to Dst prior to the injection [Ohtani et al., 2001], so the value of $20-25 \%$ obtained by a number of studies [e.g., Turner et al., 2000, 2002; Ohtani et al., 2001] may represent a lower bound on the tail current contribution. The present observation may thus be consistent with these previous results, given the extreme nature of the 31 March 2001 event and the simultaneous injection and dipolarization.

\section{Summary}

[40] The combination of global imaging, in situ, and ground-based measurements presented above strongly suggests that the Dst variations during the main phase of the 31 March 2001 storm were dominated by enhanced tail currents. While we have not been able to definitively distinguish tail currents from partial ring currents through measurement of the closure currents, we have demonstrated that the disturbance was confined to the nightside of the Earth throughout the main phase of this storm, providing strong evidence that tail currents were responsible for the observed geomagnetic disturbances.

[41] This event had very strong magnetospheric convection, driven by a very large negative $\mathrm{IMF} \mathrm{B}_{\mathrm{z}}$. The plasma sheet was unusually dense $\left(5-10 \mathrm{~cm}^{-3}\right)$ and penetrated very deeply towards the Earth, seen from observations of the plasmapause boundary at $\mathrm{L}=2$. These plasma sheet parameters imply that very strong tail currents were flowing close to the Earth, leading to stretching and distortion of the nightside plasma sheet. Strong ENA emissions were observed only near the Earth, within $\sim 4 \mathrm{R}_{\mathrm{E}}$, also consistent with stretching of the tail field. Geosynchronous measurements confirm strong stretching of the geomagnetic field, with large tail currents $\mathrm{j}=0.5 \mathrm{~A} / \mathrm{m}$ required to support the observed field configuration. Ground magnetometer measurements show that the disturbance was localized on the nightside during the main phase of the storm, a configuration which is most consistent with enhanced tail currents. ENA images demonstrate that ENA emissions from 1-60 keV were confined to the nightside until the $\sim 0630$ UT injection/ dipolarization. Following this time, the higher-energy ENA images indicate that ions began to gradient-curvature drift towards dusk, forming a partial ring current. It thus appears that tail currents dominated the disturbance until $\sim 0630$ UT, when Dst was $\sim-250 \mathrm{nT}$. Asimple calculation confirms that tail currents can produce this level of disturbance at the Earth, for the plasma and magnetic field conditions observed in this extreme event.

[42] Acknowledgments. We thank Chuck Smith for providing ACE magnetic field data andGang Lu for providing AMIE results. Dst and Sym$\mathrm{H}$ indices arefrom the World Data Center for Geomagnetism C2 in Kyoto, Japan.Geomagnetic latitudes from the IGRF model results were obtainedfrom the web pages of NASA's National Space Science Data Center. Work at Los Alamos was performed under the auspices of the U. S.Department of Energy with financial support from the NASA IMAGEprogram. Research at the University of Arizona was funded undercontract 83818 from Southwest Research Institute to the University, a subcontract under NASA contract NAS5-96020.

[43] Arthur Richmond thanks Yu. P. Maltsev and another reviewer fortheir assistance in evaluating this paper.

\section{References}

Akasofu, S.-I., and S. Chapman, On the asymmetric development of magnetic storm fields in low and middle latitudes, Planet. Space. Sci., 12, $607,1964$.

Alexeev, I. I., E. S. Belenkaya, V. V. Kalegaev, Y. I. Feldstein, and A. Grafe, Magnetic storms and magnetotail currents, J. Geophys. Res., 101, 7737, 1996.

Arykov, A. A., and Yu. P. Maltsev, Direct-driven mechanism for geomagnetic storms, Geophys. Res. Lett., 23, 1689, 1996.

Bame, S. J., D. M. McComas, M. F. Thomsen, B. L. Barraclough, R. C. Elphic, J. P. Glore, J. T. Gosling, J. C. Chavez, E. P. Evans, and F. J. Wymer, Magnetospheric plasma analyzer for spacecraft with constrained resources, Rev. Sci. Instr., 64, 1026, 1993.

Belian, R. D., G. R. Gisler, T. E. Cayton, and R. Christensen, High Z energetic particles at geosynchronous orbit during the great solar proton event of October 1989, J. Geophys. Res., 97, 16,897, 1992.

Brandt, P. C., S. Barabash, E. C. Roelof, and C. J. Chase, Energetic neutral atom imaging at low altitudes from the Swedish microsatellite Astrid: Extraction of the equatorial ion distribution, J. Geophys. Res., 106, 25,731, 2001.

Brandt, P. C., S. Ohtani, D. G. Mitchell, M.-C. Fok, E. C. Roelof, and R. Demajistre, Global ENA observations of the storm mainphase ring current: Implications for skewed electric fields in the inner magnetosphere, Geophys. Res. Lett., 29(20), 1954, doi:10.1029/2002GL015160, 2002.

Burch, J. L., IMAGE mission overview, Space Sci. Rev., 91, 1, 2000.

Burton, R. K., R. L. McPherron, and C. T. Russell, An empirical relationship between interplanetary conditions and Dst, J. Geophys. Res., 80, 4204, 1975.

Campbell, W. H., Geomagnetic storms, the Dst ring-current myth and lognormal distributions, J. Atmos. Terr. Phys., 58, 1171, 1996.

Chakrabarti, S. A., EUV (300-900 ̊ spectrum of polar cap and cusp emissions near local noon, J. Geophys. Res., 90, 4421, 1985.

Clauer, C. R., and R. L. McPherron, Mapping the local time-universal time development of magnetospheric substorms at midlatitudes, J. Geophys. Res., 79, 2811, 1974.

Clauer, C. R., I. I. Alexeev, E. S. Belenkaya, and J. B. Baker, Special features of the 24-27 September 1998 storm during high solar wind dynamic pressure and northward IMF, J. Geophys. Res., 106, 25,695, 2001.

Clauer, C. R., M. W. Liemohn, J. U. Kozyra, and M. L. Reno, The relationship of storms and substorms determined from mid-latitude ground-based magnetic maps, in On the Relationship Between Storms and Substorms, Geophys. Monogr. Ser., AGU, Washington, D. C., in press, 2002.

De Michelis, P., I. A. Daglis, and G. Consolini, Average terrestrial ring current derived from AMPTE/CCE-CHEM measurements, J. Geophys. Res., 102, 14,103, 1997.

Dessler, A. J., and E. N. Parker, Hydromagnetic theory of geomagnetic storms, J. Geophys. Res., 64, 2239, 1959.

Dremukhina, L. A., Y. I. Feldstein, I. I. Alexeev, V. V. Kalegaev, and M. E. Greenspan, Structure of the magnetospheric magnetic field during magnetic storms, J. Geophys. Res., 104, 28,351, 1999.

Elphic, R. C., M. F. Thomsen, J. E. Borovsky, and D. J. McComas, Inner edge of the electron plasma sheet: Empirical models of boundary location, J. Geophys. Res., 104, 22,679, 1999.

Frank, L. A., Direct detection of asymmetric increases of extraterrestrial "ring current" proton intensities in the outer radiation zone, J. Geophys. Res., 75, 1263, 1970.

Fujii, R., H. Fukunishi, S. Kokubun, M. Sugiura, F. Tohyama, H. Hayakawa, K. Tsuruda, and T. Okada, Field-aligned current signatures during the March 13-14, 1989 great magnetic storm, J. Geophys. Res., 97, 10,703, 1992.

Gentieu, E. P., R. W. Eastes, P. D. Feldman, and A. B. Christensen, The ultraviolet spectrum of a dayside aurora: 530-1500 А, Can. J. Phys., 67, $82,1989$.

Gonzalez, W. D., J. A. Joselyn, Y. Kamide, H. W. Kroehl, G. Rostoker, B. T. Tsurutani, and V. M. Vasyliunas, What is a geomagnetic storm?, J. Geophys. Res., 99, 5771, 1994.

Greenspan, M. E., and D. C. Hamilton, A test of the Dessler-ParkerSckopke relation during magnetic storms, J. Geophys. Res., 105, 5419, 2000 .

Häkkinen, L. V. T., T. I. Pulkkinen, H. Nevanlinna, R. J. Pirjola, and E. I. Tanskanen, Effects of induced currents on Dst and on magnetic variations 
at midlatitude stations, J. Geophys. Res., 107(A1), 1014, doi:10.1029/ 2001JA900130, 2002

Hamilton, D. C., G. Gloeckler, F. M. Ipavich, W. Stüdemann, B. Wilken, and G. Kremser, Ring current development during the great geomagnetic storm of February 1986, J. Geophys. Res., 94, 14,343, 1988

Henderson, M. G., G. D. Reeves, H. E. Spence, R. B. Sheldon, A. M. Jorgensen, J. B. Blake, and J. F. Fennell, First energetic neutral atom images from Polar, Geophys. Res. Lett., 24, 1167, 1997.

Iyemori, T., and D. R. K. Rao, Decay of the Dst field of geomagnetic disturbance after substorm onset and its implication to storm-substorm relation, Ann. Geophys., 14, 608, 1996

Kamide, Y., et al., Current understanding of magnetic storms: Storm-substorm relationships, J. Geophys. Res., 103, 17,705, 1998.

Kaufmann, R. L., Substorm currents: Growth phase and onset, J. Geophys. Res., 92, 7471, 1987.

Korth, H., M. F. Thomsen, J. E. Borovsky, and D. J. McComas, Plasma sheet access to geosynchronous orbit, J. Geophys. Res., 104, 25,047, 1999.

Liemohn, M. W., J. U. Kozyra, M. F. Thomsen, J. L. Roeder, G. Lu, J. E. Borovsky, and T. E. Cayton, Dominant role of the asymmetric ring current in producing the stormtime Dst*, J. Geophys. Res., 106, 10,883, 2001.

Lui, A. T. Y., D. J. Williams, E. C. Roelof, R. W. McEntire, and D. G. Mitchell, First composition measurements of energetic neutral atoms, Geophys. Res. Lett., 23, 2641, 1996.

Maltsev, Y. P., and A. A. Ostapenko, Comment on "Evaluation of the tail current contribution to Dst" by N. E. Turner et al., J. Geophys. Res. 107(A1), 1010, doi:10.1029/2001JA900098, 2002.

McComas, D. J., S. J. Bame, P. Barker, W. C. Feldman, J. L. Phillips, P. Riley, and J. W. Griffee, Solar Wind Electron Proton Alpha Monitor (SWEPAM) for the Advanced Composition Explorer, Space Sci. Rev., 86, $563,1998$.

Mitchell, D. G., et al., High Energy Neutral Atom (HENA) imager for the IMAGE mission, Space Sci. Rev., 91, 67, 2000.

Mitchell, D. G., K. C. Hsieh, C. C. Curtis, D. C. Hamilton, H. D. Voss, E. C. Roelof, and P. C. Brandt, Imaging two geomagnetic storms in energetic neutral atoms, Geophys. Res. Lett., 28, 1151, 2001

Moore, T. E., M.-C. Fok, J. D. Perez, and J. P. Keady, Microscale effects from global hot plasma imagery, in Cross-Scale Coupling in Space Plasmas, Geophys. Monogr. Ser., vol. 93, edited by J. L. Horowitz, N. Singh, and J. L. Burch, pp. 37, AGU, Washington, D. C., 1995.

Ober, D. M., M. F. Thomsen, and N. C. Maynard, Observations of magnetopause and bow shock crossings from geosynchronous orbit on March 31, 2001, J. Geophys. Res., 107(A8), 1206, doi:10.1029/2001JA000284, 2002

Ohtani, S., M. Nosé, G. Rostoker, H. Singer, A. T. Y. Lui, and M. Nakamura, Storm-substorm relationship: Contribution of tail current to Dst, J. Geophys. Res., 106, 21,199, 2001.

Paresce, F., S. Chakrabarti, R. Kimble, and S. Bowyer, The 300- to 900spectrum of a nightside aurora, J. Geophys. Res., 88, 10,247, 1983.

Pollock, C. J., et al., Medium Energy Neutral Atom (MENA) imager for the IMAGE mission, Space Sci. Rev., 91, 113, 2000.

Pollock, C. J., et al., First medium energy neutral atom (MENA) images of Earth's magnetosphere during substorm and storm-time, Geophys. Res. Lett., 28, 1147, 2001

Rees, M. H., Physics and Chemistry of the Upper Atmosphere, Cambridge Univ. Press, New York, 1989.

Reeves, G. D. et al., IMAGE, POLAR, and geosynchronous observations of substorm and ring current ion injection, in The Storm-Substorm Relationship, Geophys. Monogr. Ser., AGU, Washington, D. C., in press, 2002.
Reinisch, B. W., et al., The Radio Plasma Imager investigation on the IMAGE spacecraft, Space Sci. Rev., 91, 319, 2000.

Roelof, E. C., Energetic neutral atom image of a storm-time ring current, Geophys. Res. Lett., 14, 652, 1987.

Rufenach, C. L., R. F. Martin Jr., and H. H. Sauer, A study of geosynchronous magnetopause crossings, J. Geophys. Res., 94, 15,125, 1989.

Sandel, B. R., et al., The Extreme Ultraviolet Imager investigation for the IMAGE mission, Space Sci. Rev., 91, 197, 2000.

Sckopke, N., A general relation between the energy of trapped particles and the disturbance field near the Earth, J. Geophys. Res., 71, 3125, 1966.

Shiokawa, K., C.-I. Meng, G. D. Reeves, F. J. Rich, and K. Yumoto, A multievent study of broadband electrons observed by the DMSP satellites and their relation to red aurora observed at midlatitude stations, J. Geophys. Res., 102, 14,237, 1997.

Singer, H. J., L. Matheson, R. Grubb, A. Newman, and S. D. Bouwer, Monitoring space weather with the GOES magnetometers, in GOES-8 and Beyond, SPIE Conf. Proc., vol. 2812, edited by E. R. Washwell, SPIE, Bellingham, Wash., 1996.

Siscoe, G. L., and H. E. Petschek, On storm weakening during substorm expansion phase, Ann. Geophys., 15, 211, 1997.

Smith, C. W., M. H. Acuña, L. F. Burlaga, J. L'Heureux, N. F. Ness, and J. Scheifele, The ACE magnetic fields experiment, Space Sci. Rev., 86, 613, 1998

Sugiura, M., and T. Kamei, Equatorial Dst index 1957-1986, IAGA Bull., 40, 1991.

Thomsen, M. F., D. J. McComas, G. D. Reeves, and L. A. Weiss, An observational test of the Tsyganenko (T89a) model of the magnetospheric field, J. Geophys. Res., 101, 24,827, 1996.

Tsyganenko, N. A., Global quantitative models of the geomagnetic field in the cislunar magnetosphere for different disturbance levels, Planet. Space Sci., 35, 1347, 1987.

Tsyganenko, N. A., and D. G. Sibeck, Concerning flux erosion from the dayside magnetopause, 99, 13,425, 1994.

Turner, N. E., D. N. Baker, T. I. Pulkkinen, and R. L. McPherron, Evaluation of the tail current contribution to Dst, J. Geophys. Res., 105, 5431, 2000.

Turner, N. E., T. I. Pulkkinen, D. N. Baker, and R. L. McPherron, Reply, J. Geophys. Res, 107(A1), 1011, doi:10.1029/2001JA900099, 2002.

Wygant, J., D. Rowland, H. J. Singer, M. Temerin, F. Mozer, and M. K. Hudson, Experimental evidence on the role of the large spatial scale electric field in creating the ring current, J. Geophys. Res., 103, 29,527, 1998.

P. C. Brandt and D. G. Mitchell, Johns Hopkins University, Applied Physics Laboratory, Laurel, MD 20723, USA. (brandpc1@jhuapl.edu; Donald.G.Mitchell@jhuapl.edu)

C. R. Clauer, University of Michigan, Space Physics Research Lab, Ann Arbor, MI 48109, USA. (rclauer@umich.edu)

H. O. Funsten, M. G. Henderson, G. D. Reeves, R. M. Skoug, and M. F. Thomsen, MS D466, Los Alamos National Laboratory, Los Alamos, NM 87545, USA. (hfunsten@lanl.gov; mghenderson@lanl.gov; gdreeves@ lanl.gov; rskoug@lanl.gov; mthomsen@lanl.gov)

J.-M. Jahn, D. J. McComas, and C. J. Pollock, Southwest Research Institute, Instrumentation and Space Research Division, San Antonio, TX 78238, USA. (jjahn@swri.edu; dmccomas@swri.edu; cpollock@swri.edu) B. R. Sandel, University of Arizona, Lunar and Planetary Lab, Tucson, AZ 85721, USA. (sandel@vega.lpl.arizona.edu)

H. J. Singer, NOAA Space Environment Center, Boulder, CO 80305, USA. (hsinger@sec.noaa.gov) 